\title{
The impact of the economic crisis and policy actions on GHG emissions from road transport in Spain
}

\author{
Natalia Sobrino , Andres Monzon
}

H I G H L I G H T S

- Drivers contributing to GHG emissions of road transport are identified and analyzed.

- Decomposition analysis based on Modified Laspeyres Index (MLI) is applied to the Spanish case.

- Economic crisis and changes in mobility patterns and GHG emissions are analyzed.

- Policies for the decarbonization of road transport are recommended.

\begin{abstract}
A B S T R A C T
Road traffic is the greatest contributor to the carbon footprint of the transport sector and reducing it has become one of the main targets of sustainable transport policies. An analysis of the main factors influencing greenhouse gas (GHG) emissions is essential for designing new energy- and environmentally efficient strategies for the road transport. This paper addresses this need by (i) identifying factors which influence the carbon footprint, including traffic activity, fuel economy and socioeconomic development; and (ii) proposing a methodological framework which uses Modified Laspeyres Index decomposition to analyze the effect of important drivers on the changes in emissions of road transport in Spain during the period from 1990 to 2010 . The results demonstrate that the country's economic growth has been closely linked to the rise in GHG emissions. The innovative contribution of this paper is the special analysis of the changes in mobility patterns and GHG emissions during the economic crisis, when, for the first time, Spanish road traffic emissions decreased. The reduction of road transport and improved energy efficiency has been powerful contributors to this decrease, demonstrating the effectiveness of energysaving measures. On the basis of this analysis, several tailored policy recommendations have been suggested for future implementation.
\end{abstract}

\section{Introduction}

Spain ranks fifth out of the 27 European countries in terms of energy consumption in the road transport sector and 12 th in energy consumption per capita (EUROSTAT, 2013a). Impacts to the environment posed by road traffic, such as energy security and global warming, have been some of the main concerns in recent sustainable transportation policies. A sustainable transport system requires that the movement of people and goods occur in an environmentally, socially and economically viable way: mobility for any purpose constitutes a means rather than an end (WCED, 1987). Many transport strategies have focused on sustainable development. In the case of Spain, climate change mitigation measures in road transport have been applied through different energy-saving and efficiency strategies in recent years. The Ministry of Industry, Energy and Tourism introduced the National Energy Efficiency Strategy in 2004, which has given rise to three successive action plans. The current Energy Saving and Efficiency Action Plan 2011-2020 (IDAE, 2011) aims to reduce the nation's total energy consumption by $20 \%$ by 2020 ; one-third of this target should be achieved by savings in the road transport sector.

The last few decades, however, have seen remarkable growth in road transport activity. In Spain, from 1990 to 2010, road passenger mobility (passenger-km) rose by $48.65 \%$ and freight transportation 


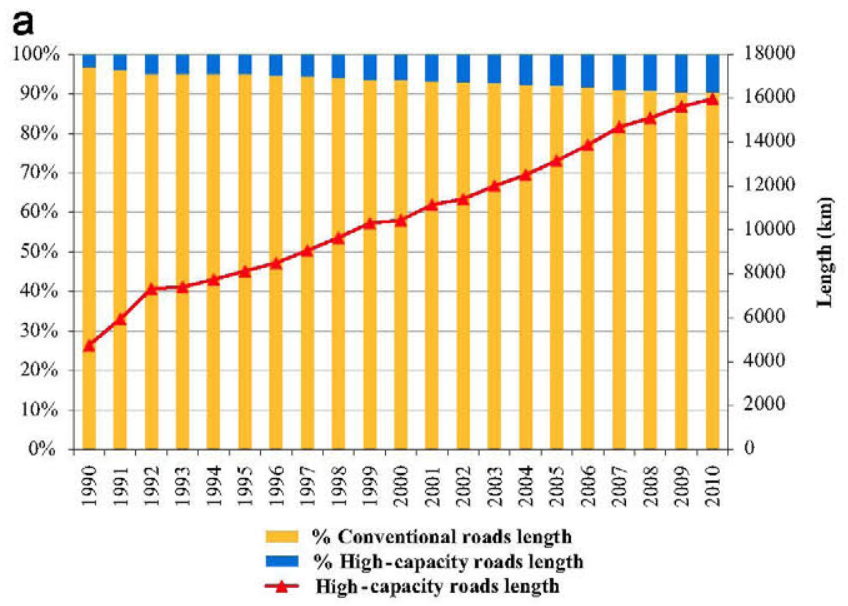

b

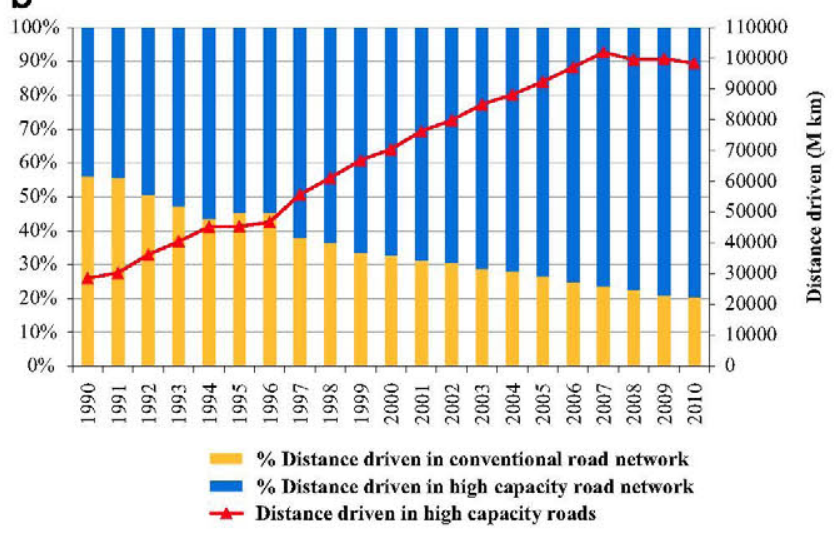

Fig. 1. (a) Spanish road network length; (b) distance driven by road type. . Source (MF, 2012)

activity (ton-km) increased by $64.8 \%$ (MF, 2012). This increase in traffic activity was marked by the expansion of the Spanish road network, especially high-capacity roads. The evolution of the network and the distances traveled on each type of road are illustrated in Fig. 1. Although the high-capacity road network represents only $10 \%$ of the length of the country's overall road network, the significant investment in road infrastructure has favoured the expansion of high-capacity roads over conventional roads (Fig. 1a). Indeed, in 2010, the total length of the high-capacity road network was 3.11 times that of the network in 1990, reaching nearly $16,000 \mathrm{~km}$ in 2010 (MF, 2012). This commitment to developing a well-established high-capacity network has led to an increase in the distances traveled on these routes (see Fig. 1b). Higher speeds, on the one hand, reduce trip times; on the other hand, however, this produces a rebound effect as vehicles travel greater distances, thereby increasing the overall energy consumption and GHG emissions. In fact, in 2010, the distance driven on high-capacity roads represented $80 \%$ of the total distance driven on the entire road network. Fig. 1.b shows that the distances driven on high-capacity roads increased substantially from 1997 to 2007, when they reached more than 100 billion kilometers annually. In contrast, there was a slight decrease from 2007 to 2010, with the most significant drop between 2007 and 2008.

The expansion of the network - especially of high-capacity roads - and the rise in demand for road transport have been followed by a respective increase in energy consumption and emissions. Road traffic remains the mode which consumes the most energy, representing $80 \%$ of total transportation energy consumption (ODYSSEE, 2012). Fig. 2 presents the evolution of total GHG emissions produced by the transport sector and those specifically linked to road traffic in Spain from 1990 to 2010. Despite the increase in transport emissions in absolute terms during this period, the share of road transport in the total national transportation emissions has remained steady at $90 \%$. This confirms that the increase in transport activity was mainly produced by the expansion of road traffic. From 1990 to 2007 there was a continuous rise in GHG emissions in the road transport sector, with an average annual increase of 5\%. From 2007 to 2010, however, there was a steady decline in emissions, with the most significant decrease occurring between 2007 and 2009. During these years, the effects of the crisis became more and more apparent; associated mobility of passengers and goods decreased, mainly due to the decline in working activity. Both of these factors were also significantly affected by the increase in oil prices during this period (ODYSSEE, 2012).

\subsection{Review of previous studies of transport in Spain}

The noticeable growth in road activity and GHG emissions over the last few decades justifies a detailed analysis of their explanatory factors. Previous studies analyzing the climate change impacts of road transport in Spain have considered all transport modes together. The majority of these studies were published after 2004, when energy-saving and sustainability policies began to be implemented on a wider scale. Pérez-Martínez and Monzón (2008) showed that there is a clear dependence on road transport in Spain. They argued that the increase in road traffic during the period from 1990 to 2005 was due to a rise in the motorization rate and in transportation demand, brought about by an increase in private mobility by car. Meanwhile, Mendiluce et al. (2010) identified the key factors driving the evolution of Spain's energy intensity levels using decomposition analysis. The results of their study show that the economic structure and strong transport growth have been the main factors driving the changes in energy intensity in Spain. Road mobility has demanded 50\% more energy between 1995 and 2006, both in freight and passenger cars. The rise in passenger car use was caused by the increase in population and per capita income, urban sprawl and the dieselization of the fleet, which, while improving overall energy efficiency, had a rebound effect of increasing travel distances. For road freight transport, the main factors which have deteriorated the energy intensity were construction activity and an increase in the demand for short-distance delivery of supplies, which has raised light-duty vehicle use (Mendiluce et al. 2010). In the meantime, PérezMartínez (2010) analyzed trends in freight transport and GHG emissions in Spain from 1990 to 2007 using decomposition techniques. Freight transportation in Spain contributes to $8.5 \%$ of Spain's emissions and increased activity, the large modal share of road transport and economic growth are the main factors which have brought about this increase. In turn, Mendiluce and Del Río (2010) examined the determinants of passenger transport evolution in terms of energy dependence and GHG emissions. After the decomposition analysis, they concluded that the purchase of diesel vehicles has been the main driver of energy consumption for private car transport (influenced by per capita income). The total distance traveled per capita has grown significantly, with a consequent effect on energy consumption. While diesel vehicles offer better energy efficiency, this has not been enough to offset the growth of the transport sector (Mendiluce and Del Río, 2010). Mendiluce and Schipper (2011) then determined that transportation is the main contributor to Spain's emissions increase, which is mostly due to road-based transport modes. If energy efficiency has offered some benefits, these have not been enough to counter the dieselization of the fleet and the increase in traffic activity due to the rebound effect. The authors also highlighted the development of Spanish transport infrastructure and the heavy investment in 


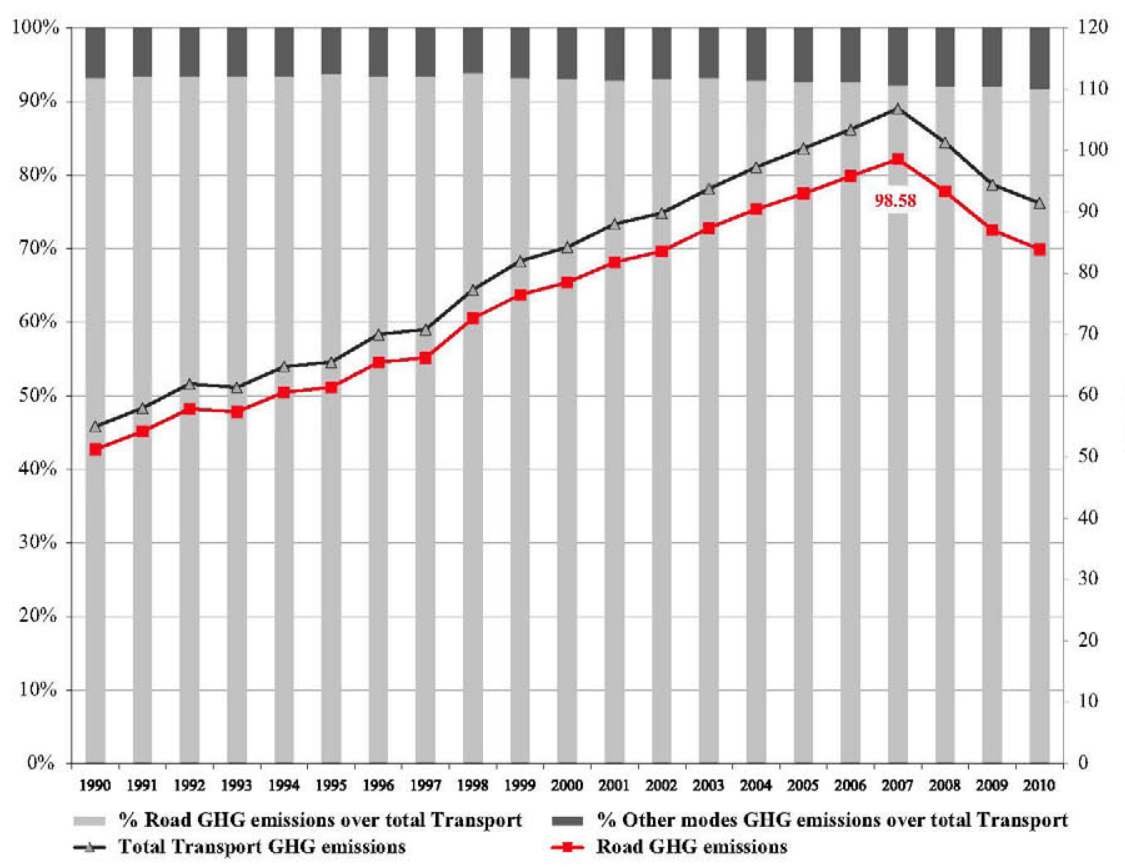

Fig. 2. GHG emissions trends in Spain. .

Source: (EUROSTAT, 2013b)

the road transport network. Then, Gonzalez and Marrero (2012) established the existence of a significant indirect, negative effect on $\mathrm{CO}_{2}$ emissions caused by the dieselization of passenger cars, which offset the direct, positive effect of the efficiency offered by these vehicles. Most recently, Pérez-López et al. (2013) analyzed the evolution of the GHG emissions of three Spanish motorways in the 2005-2010 period using a bottom-up methodology and considering only emissions factors and activity. They found that activity is the major parameter contributing to emissions, while the vehicle fleet composition also affects the level of emissions.

These studies analyzed the transport sector in Spain up to 2008 and thus did not cover the economic crisis, whose effects were only beginning to be seen at that time. Pérez-López et al. (2013) were the only authors to partially analyze the financial crisis, but they did not consider the influence of socioeconomic factors, which are key to analyzing a period of economic change. It is therefore of interest to conduct a more detailed study of the drivers, including socioeconomic factors, which have influenced road emissions during economic crisis.

\subsection{Study aims and structure}

The aim of this study is to understand the key factors influencing the GHG emissions levels of road transportation from 1990 to 2010 in Spain and to propose new road transport strategies to reduce its carbon footprint. The study proposes a methodological framework based on Modified Laspeyres Index (MLI) decomposition analysis with which to examine the main factors influencing the GHG emissions of road traffic in Spain, including economic crisis period. The framework includes factors derived from a literature review. The results of the analysis show that this methodology is consistent, even over long periods with large changes in data values, and that it can be used as a tool for designing road transport strategies and measures to reduce climate change impacts by targeting main drivers.

This paper is organized as follows: Section 2 presents the methodological framework used for the analysis and includes an examination of potential factors driving road transport carbon footprint trends.
This is followed by a description of the decomposition analysis model and the data sources used for this study. In Section 3, the methodology is applied to identify trends in Spanish road transport emissions during the twenty-year period from 1990 to 2010; these trends in the drivers, GHG emissions and the final results are then analyzed. A discussion based on the Spanish case study is outlined in Section 4. The main findings and policy recommendations are included in the conclusions (Section 5).

\section{Methods and data}

This study follows the methodological framework presented in Fig. 3. The first step is the definition of fundamental factors which influence the GHG emissions of road transport over a period of time (Section 2.1). Based on these factors, potential drivers are chosen for analysis and to serve as input for the decomposition analysis model. These drivers constitute the multiplicative decomposition coefficients and represent relationships between the underlying factors. From the decomposition, the drivers which have the greatest influence over the change in emissions during the selected period are identified. Strategies and policies are then proposed that could influence key parameters in an effort to achieve low-carbon road transport targets.

Before presenting the potential determinants of the road transport carbon footprint (see Section 2.3), the following section presents a discussion of factors, identified from the literature, which constitute important contributors to the changes in the carbon footprint of road transport.

\subsection{Underlying factors affecting the carbon footprint of road transport}

Decomposition of the growth of emissions into affecting factors is key to developing policies and strategies that strive towards more environmentally efficient mobility. Most transportation studies are focused on the decomposition of national $\mathrm{CO}_{2}$ emissions for transport in general, distinguishing only between passenger and freight 
transportation (Lakshmanan and Han, 1997; Lipscy and Schipper; 2013; Mazzarino, 2000; Mendiluce and Schipper, 2011; Schipper et al., 2000; Schipper et al., 2011; Scholl et al., 1996; Timilsina and Shrestha, 2009a, 2009b; Wang et al., 2011; Zhang et al., 2011).

Several studies have analyzed different specific aspects of road transport, such as passenger, freight or car travel (He et al., 2005; Kwon, 2005; Li et al., 2013; Lu et al., 2007; Papagiannaki and Diakoulaki, 2009; Piecyk and McKinnon, 2010; Yan and Crookes, 2009). The main factors examined in these studies are activity and fuel efficiency. For example, Kwon (2005), taking a simple approach, represented the $\mathrm{CO}_{2}$ emissions from car travel by population, affluence and vehicle technology. The study found that car occupancy rates have decreased significantly over the years and it was determined that, in the case of $\mathrm{CO}_{2}$ emissions from car travel in Great Britain, the affluence factor (distance traveled per person) was the driving force behind the growth of emissions over the last 30 years. He et al. (2005) identified three

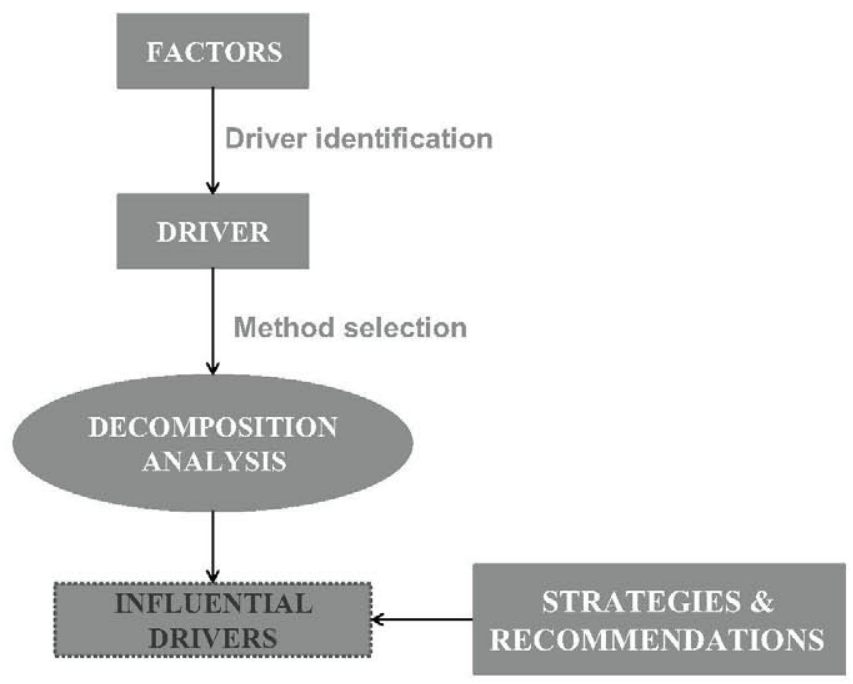

Fig. 3. Methodological framework. important factors related to fuel consumption of road transport in China: vehicle population, average mileage and fuel economy. The analysis suggested that improvements in vehicle fuel economy could potentially lead to significant fuel consumption savings. Additional factors are taken into account in Lu et al. (2007), who decomposed the total $\mathrm{CO}_{2}$ emissions from highway vehicles into the emission coefficient, fuel intensity, vehicle ownership, population intensity and economic growth. This study adopted a decomposition approach to explore the impacts of these five factors on the total $\mathrm{CO}_{2}$ emissions from highway vehicles in different countries. They found that rapid economic growth and increased vehicle ownership were the most important factors contributing to the rise in $\mathrm{CO}_{2}$ emissions, whereas population intensity contributed significantly to a decrease in emissions. The socioeconomic factors proved to be of great importance in this decomposition analysis. Afterwards, Papagiannaki and Diakoulaki (2009) analyzed the $\mathrm{CO}_{2}$ emissions from passenger cars by examining vehicle ownership, fuel mix, annual mileage, engine capacity and vehicle technology. The evolution of emissions in Greece and Denmark was examined during the period from 1990 to 2005. The results revealed that vehicle ownership was the most influential factor in the increase in emissions in Greece. In the case of Denmark, the shift towards cars with greater cylinder capacity was the main factor responsible for $\mathrm{CO}_{2}$ emissions changes. Meanwhile, Yan and Crookes (2009) estimated the energy demand of road transport in China as a function of such factors as fuel economy, fleet composition and average annual mileage by vehicle type.

In the case of freight, the factors affecting emissions are more disaggregated. Pérez-Martínez (2010) decomposed freight emissions in Spain into activity, modal change, fuel mix and fuel efficiency. Recently, Li et al. (2013) considered the emission coefficient, vehicle fuel intensity, market concentration level, freight transportation distance, market share of road freight transport and economic growth, among others, as factors influencing the $\mathrm{CO}_{2}$ emissions of road freight transport in China. Piecyk and McKinnon (2010) defined four levels of influential factors in freight transport: structural, commercial, operational and functional. These were then split into the key variables used for their

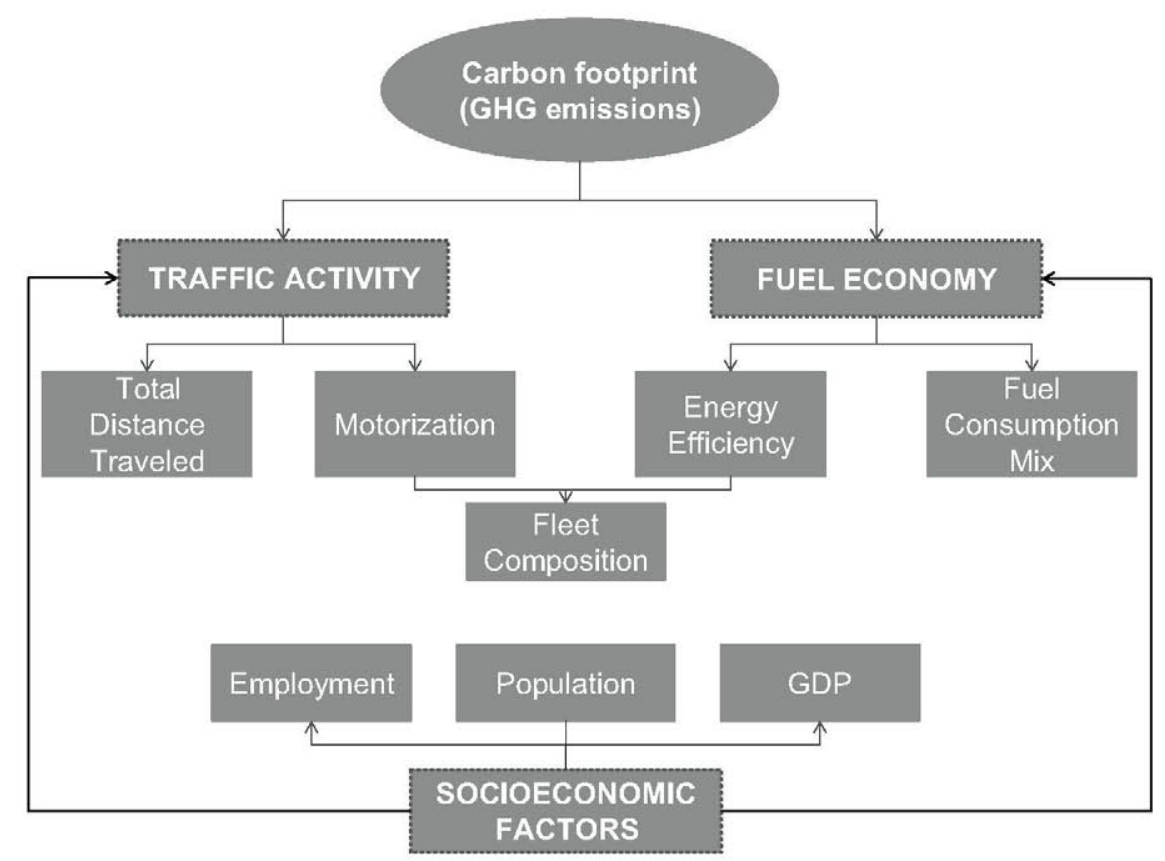

Fig. 4. Factors influencing the carbon footprint of road transport. 
analysis: value density, modal split, handling factor, average length of haul, load factor, empty running, fuel efficiency and carbon intensity of fuel.

In general terms, then, the carbon footprint of road transport due to vehicle traffic is influenced by two main factors (see Fig. 4): traffic activity and fuel economy. Activity mainly depends on the total distance driven by vehicles in the total network and the motorization. Fuel economy is determined by the fuel mix (the distribution of fuel consumption among different types of fuels) and the vehicle energy efficiency, both of which are dependent on the vehicle fleet composition (engine size, technology penetration, age, etc.). Both activity and fuel economy are also influenced by socioeconomic factors: population, GDP and employment.

\subsection{Decomposition analysis: $M L I$}

Index decomposition methodologies, such as the Laspeyres Index (LI) and Divisia Index (DI), are used to identify relevant factors that influence changes in $\mathrm{CO}_{2}$ emissions, energy use and energy intensity and are helpful in establishing policies aimed at reducing environmental and energy impacts. A large number of decomposition methods have been developed and discussed in different studies (Ang, 2004; Ang et al., 2009), each with certain advantages and disadvantages. The most commonly used decomposition methods in transport energy and emissions studies are the LI and DI (Ang, 2004). However, the existence of a residual term leads to uncertainty as to the meaningfulness of the results (Ang and Choi, 1997; Ang and Zhang, 2000). In the case of the DI, the additive and multiplicative Logarithmic Mean Divisia Index (LMDI) was created to overcome the issue of the residual term by applying a logarithmic mean weight function to all factors (Ang et al., 1998; Ang and Liu, 2001). To deal with this issue in the LI, Sun (1998) proposed the Refined Laspeyres Index (RLI) method, in which the interaction terms are distributed equally among all factors according to the "jointly created and equally distributed" principle. Recently, Mishina et al. (2011) proposed the Modified Laspeyres Index (MLI) which is based on the RLI, but "attributes the interaction terms to the related factors according to the changes in each factor and distributes them in a manner proportional to a symmetrical rate of the changes". MLI methods provide more accurate and reliable decomposition than the RLI or LMDI, particularly in cases where some factors change positively and others negatively (Mishina and Muromachi, 2012).

This study uses the additive MLI approach to conduct a timeseries decomposition by comparing yearly data and adding up the annual changes over a specific period (detailed in Appendix A). The decomposition analysis focuses on several factors mentioned above which constitute important driving forces behind changes in GHG emissions from road transport, namely energy consumption, total annual mileage, total number of vehicles, population, employment and GDP.

The general equation used to calculate the amount $Q_{t}$ of GHG emissions in year $t$ (tons of $\mathrm{CO}_{2}$-eq) from road transport is the following:

$Q_{t}=\frac{Q_{t}}{E C_{t}} \times \frac{E C_{t}}{T_{t}} \times \frac{T_{t}}{V F_{t}} \times \frac{V F_{t}}{P_{t}} \times \frac{P_{t}}{E P_{t}} \times \frac{E P_{t}}{G D P_{t}} \times G D P_{t}$

where $E C_{t}$ is the total energy consumption from road transport for year $t(\mathrm{TJ}) ; T_{t}$, the total distance driven by vehicles in year $t\left(10^{6} \mathrm{~km}\right)$; $V F_{t}$, the number of motor vehicles for year $t\left(10,000\right.$ vehicle units); $P_{t}$, the population in year $t\left(10,000\right.$ inhabitants); $E P_{t}$, the employed population (10,000 inhabitants); and $G D P_{t}$, the Gross Domestic Product in year $t\left(10^{6}\right.$ euro, reference year 2000$)$. Eq. (1) can also be rewritten as

$Q_{t}=C_{t} \times E_{t} \times U_{t} \times M_{t} \times J_{t} \times W_{t} \times G D P_{t}$

where $C_{t}, E_{t}, U_{t}, M_{t}, J_{t}, W_{t}$ and $G D P_{t}$ are the main drivers influencing GHG emissions from road transport and are described in Table 1.

In additive MLI decomposition, the change in $Q(\Delta Q)$ recorded in time $t$ in comparison with the level in a base year $t=0$ is calculated as follows:

$$
\begin{aligned}
\Delta Q & =Q^{t}-Q^{0}=C^{t} E^{t} U^{t} M^{t} J^{t} W^{t} G D P^{t}-C^{0} E^{0} U^{0} M^{0} J^{0} W^{0} G D P^{0} \\
& =\Delta C+\Delta E+\Delta U+\Delta M+\Delta J+\Delta W+\Delta G D P
\end{aligned}
$$

where $\Delta C, \Delta E, \Delta U, \Delta M, \Delta J, \Delta W$ and $\Delta G D P$ are the index levels of the changes in GHG emissions brought about by each driver. The change in $Q$ can also be expressed as the sum of the three groups of index levels: fuel economy, traffic activity and socioeconomic factors (see Fig. 5).

Table 1

Identification of drivers influencing $\mathrm{GHG}$ emissions from road transport.

Drivers influencing GHG Description

emissions
Input

determinants

for

decomposition

analysis

$C_{t}$ - Carbon intensity of road Carbon intensity of road transport is defined as the amount of $\mathrm{CO}_{2}$-eq emitted per unit of energy consumption by road $C_{t}=Q_{t} / E C_{t}$ transport transport. It is mainly dependent on the type of fossil fuel used (carbon efficiency of fuel). A decrease means that there is an improvement in the carbon efficiency of the fuel combustion.

$E_{t}$ - Energy intensity of road Energy intensity of road transport is expressed as the total energy consumption per total kilometers driven in the road $E_{t}=E C_{t} / T_{t}$ transport network. A decrease in energy intensity can be explained by improvements in energy efficiency: greater engine efficiency, improved driving behavior, a shift from gasoline to more efficient (i.e. diesel) vehicles or better highway design and management.

$U_{t}$ - Use intensity Use intensity of a road network is expressed as the total number of kilometers driven per vehicle. An increase could $U_{t}=T_{t} / V F_{t}$ mean that there is a rise in the annual mileage per vehicle.

$M_{t}$ - Motorization rate The motorization rate is the total number of vehicles per inhabitant. An increase in motorization rate is correlated with $M_{t}=V F_{t} / P_{t}$ economic growth.

J - Job intensity Job intensity is the relationship between the population and the number of employed people. It is the inverse of the employment rate. An increase means that there is a decrease in the employment rate and usually correlated with a period of economic crisis.

$W_{t}$-Workers income intensity Workers income intensity is the number of employed people per unit of GDP for the year t. It is the inverse of GDP per $W_{t}=E P_{t} / G D P$ employed capita. A decrease means that employment population grows slower than GDP, so there is an increase in the productivity of the labor market. 


\subsection{Data sources}

Vehicle activity and energy consumption data for the Spanish road transport sector are collected at a national level by the Spanish government. The following paragraphs list the data sources and procedures which have been used in the decomposition analysis. Appendix B includes a table with the data used in the analyses.

a) Every year, the Spanish Road Traffic Map provides information with measurements of traffic flow at locations across the road network. The distance traveled by road vehicles is estimated from annual traffic flows at different locations (MF, 2012).

b) Vehicle fleet data are gathered by the Directorate General of Traffic (DGT), which maintains a detailed database with the number of vehicles in use by fuel type, engine capacity and technology at a provincial level. The official figures are published yearly by the Ministry of Public Works (MF, 2012).

c) Energy statistics for road transport in Spain are compiled from the sales data of fuel for road vehicles. Information about fuel consumption figures in road transport is taken from National Energy Commission (CNE, 2013).

d) Information regarding GHG emissions from road transport is taken from the Spanish GHG Inventory (MAGRAMA, 2012). This study uses the 2012 edition of the Greenhouse Gas Inventory which has compiled annual data from 1990 to 2010. The inventory estimates emissions by activity sector. The road transport category encompasses pollutant emissions produced

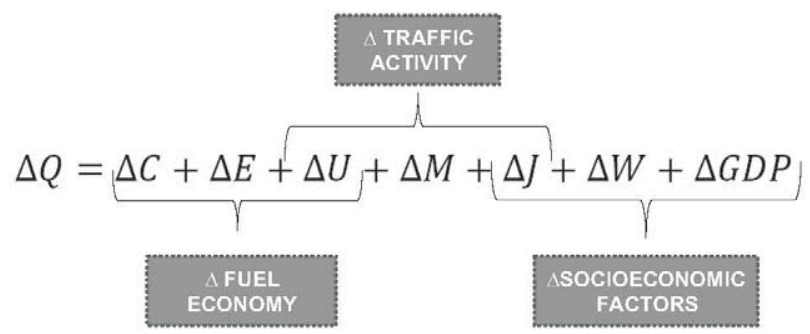

Fig. 5. Main groups of index levels of carbon footprint of road transport. by vehicle traffic whose main purpose is the road transportation of passengers and freight.

e) Finally, population, employment and GDP data are obtained from the Spanish National Statistics Institute (INE, 2013).

\section{Results}

Before obtaining the results, trends were identified in the GHG emissions and in the seven drivers over the period from 1990 to 2010 (taking 1990 as a base year). These are the input data for the MLI. Fig. 6 represents those trends over the twenty-year period. The results show that, on the one hand, drivers such as carbon intensity $(C)$, energy intensity $(E)$, job intensity $(J)$ and workers income intensity $(W)$ remained below 1990 levels and therefore had a positive influence on the reduction of GHG emissions of road transport. On the other hand, the motorization rate $(M)$ and economic growth (GDP) - and to a lesser extent road use intensity $(U)$ - were higher than in 1990 , negatively effecting emissions. It is worth noting that when the crisis started, the traffic activity drivers, as well as GDP and workers income intensity $(W)$, two of the socioeconomic growth drivers, led to a decline in GHG emissions. However, job intensity, the third socioeconomic driver, increased over the years as the employment rate grew more slowly than the total population, leading to an increase in GHG emissions during the final period.

The years analyzed are 1990-2010, inclusive, and the following subintervals have been identified:

a) 1990-1997: GHG emissions from road traffic gradually began to increase. This period was influenced by rapid motorization (M). There was an annual growth of $4 \%$ in the number of vehicles per inhabitant in this seven year period.

b) 1997-2002: GHG emissions rose continuously and more markedly. During this period, there was an improvement in energy efficiency $(E)$ due to the dieselization of the Spanish vehicle fleet. Energy intensity remained at around 90\% of 1990 levels, which meant an improvement of $10 \%$ in energy efficiency from 1990.

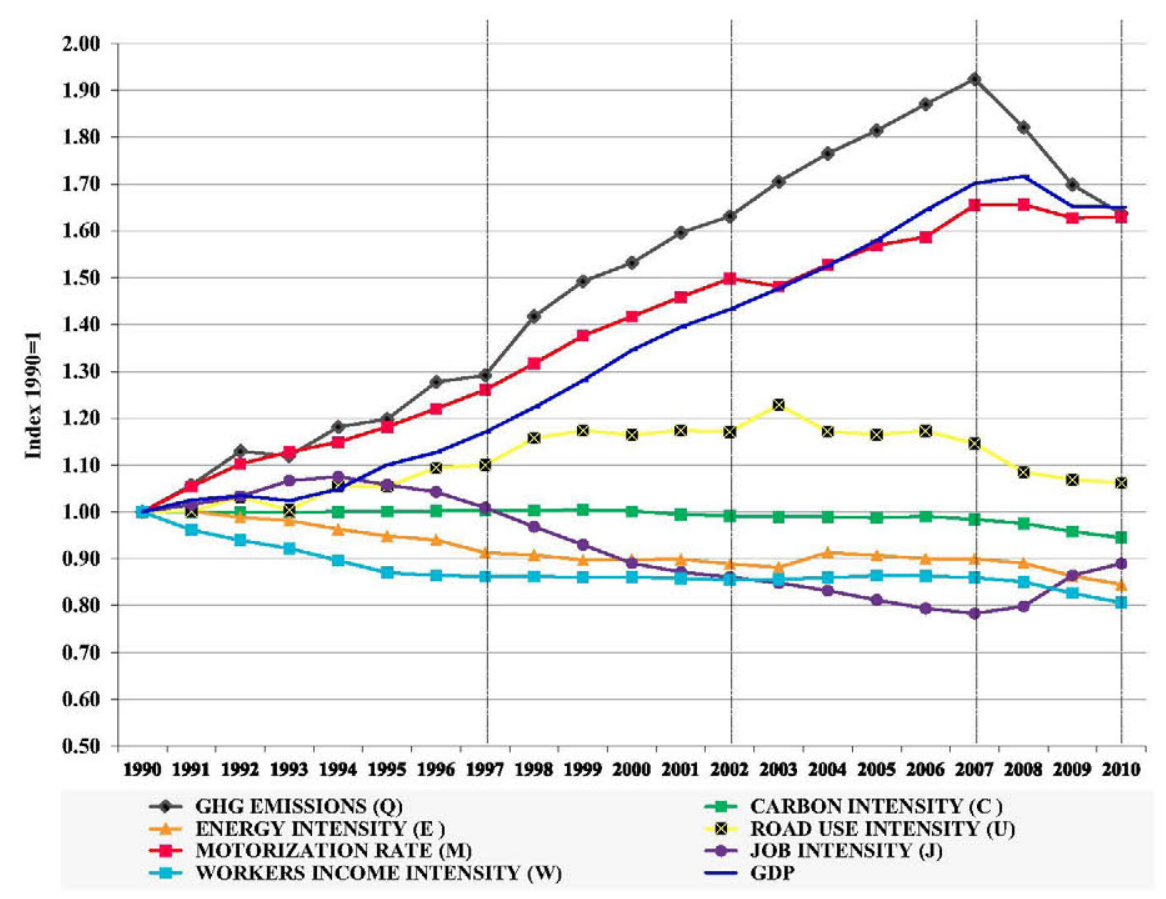

Fig. 6. Trends in GHG emissions and change drivers from road transport in Spain. 
Table 2

Results of the MLI decomposition: changes in GHG emissions due to drivers.

\begin{tabular}{llllllllll}
\hline Year & \multicolumn{6}{c}{ Index level (GHG emission unit: $10^{6}$ metric tons of $\mathrm{CO}_{2}$-eq) $)^{\mathrm{a}}$} \\
\cline { 2 - 9 } & $\Delta \boldsymbol{C}$ & $\Delta \boldsymbol{E}$ & $\Delta \boldsymbol{U}$ & $\Delta \boldsymbol{M}$ & $\Delta \mathrm{J}$ & $\Delta \boldsymbol{W}$ & $\Delta \mathrm{GDP}$ & $\Delta \boldsymbol{Q}$ \\
\hline $\mathbf{1 9 9 0 - 2 0 1 0}$ & $-\mathbf{4 . 7 0}$ & $-\mathbf{1 0 . 3 2}$ & $-\mathbf{0 . 8 8}$ & $\mathbf{3 4 . 5 5}$ & $-\mathbf{4 . 4 9}$ & $-\mathbf{1 4 . 0 4}$ & $\mathbf{3 2 . 5 1}$ & 32.63 \\
\hline
\end{tabular}

${ }^{\text {a }} \Delta C$, carbon intensity; $\Delta E$, energy intensity; $\Delta U$, road use intensity; $\Delta M$ motorization rate; $\Delta J$, job intensity; $\Delta W$, workers income intensity; $\triangle G D P$, gross domestic product; $\triangle \mathrm{Q}$ GHG emissions.

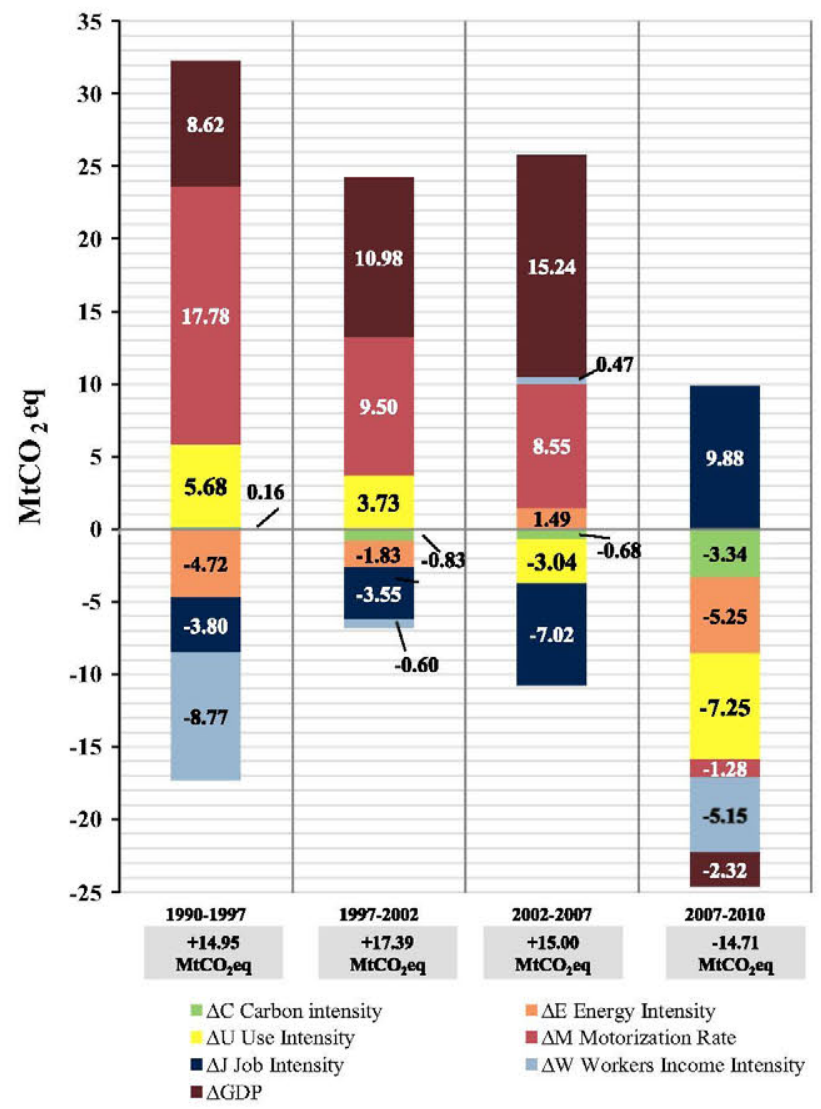

Fig. 7. Time-series decomposition distribution of the effect of the drivers.

c) 2002-2007: GHG emissions peaked in 2007. In this period, the nation experienced rapid economic growth (GDP). Evidence of this is the large increase of GDP and the increase in the employment rate (opposite to job intensity).

d) 2007-2010: GHG emissions began to decline due to the economic crisis. The GDP together with the employment rate decreased and consequently there was a reduction of road use.

The results of the MLI approach described in Section 2.2 are illustrated in Table 2 and Fig. 7. This methodology uses a timeseries decomposition of the GHG emissions trends in the Spanish road transport sector, adding up the annual changes as calculated by the decomposition methodology (Appendix A).

The net GHG emissions from road transportation increased by 32.63 million metric tons of $\mathrm{CO}_{2}$-eq from 1990 to 2010. The motorization rate $(M)$ was the major driver affecting GHG emissions; overall, this contributed to an increase of 34.55 million metric tons of emissions. This was followed by GDP, which led to 32.51 million metric tons of additional emissions. On the other hand, the drop in the energy required per kilometer $(E)$ had a positive effect on the reduction of emissions: since 1990, the total decrease came to 10.32 million metric tons. The workers income intensity $(W)$ is a special case: it had a positive effect, decreasing GHG emissions by 14.04 million of metric tons, meaning that there was an improvement in the productivity of the workforce. The job intensity $(J)$ index indicates a total reduction of 4.49 million metric tons of emissions, as the population increased more slowly than the number of employed people. Moreover, the effect of the decrease in carbon intensity $(C)$ - which produced a savings of 4.7 million metric tons - indicates an improvement in fuel efficiency.

Finally, the effect of the drivers on the GHG emissions of the four periods between 1990 and 2010 is illustrated below in Fig. 7.

a) From 1990 to 1997, GHG emissions rose by 14.63 million metric tons, with the motorization rate $(M)$ contributing most significantly to the increase (resulting 17.78 million metric tons of increasing), though it was also influenced by the economic growth (GDP) and the increase in the total number of kilometers driven per vehicle $(U)$ (8.62 and 5.68 million metric tons respectively). Energy efficiency, however, improved, resulting in a reduction of 4.72 million metric tons of emissions during this seven-year period.

b) In the 1997-2002 period, GHG emissions grew more sharply than in the preceding period, with an increase of 17.4 million metric tons in five years. In this period, economic growth (GDP) along with the motorization rate $(M)$ and road use $(U)$ were the most influential drivers providing increases of $10.98,9.50$ and 3.73 million metric tons respectively.

c) The next five years were characterized by an increase in road transport climate change impacts; reaching a peak of 98.58 million metric tons of GHG emissions in 2007 (see Fig. 2). Again, the main drivers which influenced this increase were GDP and the motorization rate $(M)$ contributing to an increase of 15.24 and 8.55 million metric tons respectively. Road use intensity $(U)$, however, improved, leading to a reduction of 3.04 million metric tons of emissions; carbon efficiency $(C)$ led to emissions savings as well. In contrast, energy efficiency $(E)$ deteriorated, increasing emissions by 1.5 million metric tons over the five-year period.

d) The final period - corresponding to the economic crisis - saw a large decrease in climate change impacts, approximately 15 million metric tons from 2007 to 2010 . Road use intensity $(U)$ and energy efficiency $(E)$ were the most important drivers for the emissions decrease, providing savings of 7.25 and 5.25 million metric tons, respectively. Workers income intensity $(W)$ also had a positive influence, with a reduction of 5.15 million metric tons of GHG emissions. Moreover, carbon efficiency $(C)$ contributed to a decrease of 3.34 million metric tons of emissions. For the first time, economic growth (GDP) and the motorization rate $(M)$ contributed to a reduction in total emissions (2.32 and 1.28 million metric tons, respectively). Finally, during this period, job intensity $(J)$ brought about an increase of 9.88 million metric tons in emissions due to the fact that the total population increased more quickly than the number of employed people.

\section{Discussion}

Several studies analyzing the Spanish transport sector, as mentioned above, have found that socioeconomic development is the main factor in the high energy demand and GHG emissions of Spanish transport. Therefore, the greatest challenge is decoupling climate change impacts from economic growth. This analysis shows similar results for the period before the economic crisis. During the recession, however, other factors, such as energy 
Table 3

Assessment of key drivers (comparison with total change in GHG emissions 1990-2010).

\begin{tabular}{|c|c|c|c|c|c|c|}
\hline & & $1990-1997$ & 1997-2002 & $2002-2007$ & $\begin{array}{l}2007- \\
2010\end{array}$ & $\begin{array}{l}1990- \\
2010\end{array}$ \\
\hline \multirow{7}{*}{$\begin{array}{l}\text { Effect of key } \\
\text { drivers on GHG } \\
\text { emissions }\end{array}$} & $\Delta C$ Carbon Intensity & - & + & + & + & + \\
\hline & $\Delta E$ Energy Intensity & ++ & + & - & ++ & ++ \\
\hline & $\Delta U$ Use Intensity & -- & - & + & ++ & + \\
\hline & $\Delta M$ Motorization Rate & ---- & -- & -- & + & --- \\
\hline & $\Delta J$ Job Intensity & ++ & + & ++ & $\begin{array}{l}-- \\
-\end{array}$ & + \\
\hline & $\begin{array}{l}\Delta W \text { Workers Income } \\
\text { Intensity }\end{array}$ & +++ & + & - & ++ & ++ \\
\hline & $\triangle \mathrm{GDP}$ & --- & -- & --- & + & --- \\
\hline $\begin{array}{l}\Delta Q \text { (GHG emissions } \\
\text { in Mt } \mathrm{CO}_{2} \text {-eq) }\end{array}$ & & +14.95 & +17.39 & +15 & -14.71 & +32.63 \\
\hline Assessment & $\begin{array}{l}\uparrow \mathrm{M} \text { and small cars; } \\
\uparrow \mathrm{U}=\text { Rapid motorization }\end{array}$ & $\begin{array}{l}\uparrow \mathrm{M} \text { and diesel cars; } \\
\uparrow \mathrm{U}=\text { Dieselization }+ \text { rebound } \\
\text { effect }\end{array}$ & $\begin{array}{l}\uparrow \mathrm{M} \text { and large engine size, } \uparrow \mathrm{U}, \\
\downarrow \mathrm{E}=\text { Inefficiency }\end{array}$ & $\begin{array}{l}\downarrow U, \uparrow E, \uparrow C=\text { Lessons from the } \\
\text { crisis }\end{array}$ & & \\
\hline Changes & $\begin{array}{l}\text { Penetration of EURO } \\
\text { technologies in the vehicle } \\
\text { fleet }\end{array}$ & $\begin{array}{l}\text { PREVER plan = purchase of } \\
\text { diesel vehicles }\end{array}$ & $\begin{array}{l}\text { Cheap diesel fuel+purchase of } \\
\text { cars with large engine capacity }\end{array}$ & $\begin{array}{l}\text { Results from } E 4 \\
\text { Strategy + biofuel } \\
\text { penetration + crisis impacts }\end{array}$ & & \\
\hline
\end{tabular}

Explanation of the effect of key drivers on $\triangle G H G$ emissions

$(+)$ Decreased emissions.

$(-)$ Increased emissions.

Large $=(++++$ or $-\ldots--)$ greater than $75 \%$.

Moderate $=(+++$ or $-\ldots--)$ from $50 \%$ to $75 \%$.

Medium $=(++$ or --$)$ from $25 \%$ to $50 \%$.

Slight $=(+$ or -$)$ from $0 \%$ to $25 \%$.

efficiency, carbon efficiency, activity or job intensity, began to have a greater influence on GHG emissions.

A qualitative scale has been developed in order to classify the corresponding effect of each driver in categories according to their magnitude - large, moderate, medium or slight - and direction increase $(-$ ) or decrease $(+)$ in GHG emissions (see Table 3 ). The table also includes a brief assessment and a summary of important changes which took place during each period. The following subsections analyze each period and discuss the transport strategies devised during the twenty-year period and beyond.

\subsection{Rapid motorization: $1990-1997$}

The seven-year period of 1990-1997 was governed by the rapid motorization of the population. Vehicle ownership was dominant and greatly influenced road use intensity. These led to an increase of GHG emissions, together with the deterioration of carbon intensity which was influenced by the gasoline consumption. To 1997 more than $80 \%$ of passenger car vehicles used gasoline as fuel (DGT, 2011). The improvement in energy efficiency, on the other hand, had a positive effect on GHG emissions in this period, brought about by the penetration of more efficient vehicles: from 1990 to 1997, the use of EURO technologies increased by 30\% (DGT, 2011). During this period, the improvement in the productivity of the labor market (decreased of workers income intensity) also influenced positively on GHG emissions.

\subsection{Dieselization effect: $1997-2002$}

In the five-year period from 1997 to 2002, the Spanish Government enacted several dieselization policies, such as the PREVER Plan 1997-2007, in an effort to reduce the age of the vehicle fleet and to eliminate leaded gasoline; helping vehicle owners to replace older cars with new ones provided a catalyst (Spanish Government, 1997). During this period, the percentage of diesel vehicles in the total fleet grew from $18.1 \%$ to $32.5 \%$, and by 2002 , the price of diesel fuel was $14 \%$ cheaper than gasoline (MF, 2012). Although diesel vehicles are more efficient than gasoline ones, as they offer better carbon and energy intensity, these policies had a negative influence on GHG emissions, causing a rebound effect by greatly increasing road use (Mendiluce et al., 2010). The growing role of diesel vehicles in Spain confirms that fiscal policies can generate changes in driver behavior. Nevertheless, such policies should be carefully controlled, as the fiscal incentive for the purchase of these vehicles, combined with lower taxation, led to a rebound effect, increasing the total annual kilometers traveled and consequently raising emissions.

\subsection{Rapid economic growth and mileage increase: $2002-2007$}

The rapid economic growth of the 2002-2007 period had a negative influence on the GHG emissions of road traffic, which reached their peak in 2007. The wealth of the Spanish population increased road transport activity. One example is the increase in engine size for passenger cars from 1997 to 2010 as Fig. 8 illustrates. In 2007, more than half of cars had an engine capacity of over $1600 \mathrm{~cm}^{3}$ and only $10 \%$ could be categorized as small cars (less than $1200 \mathrm{~cm}^{3}$ of engine capacity). Therefore, the purchase of cars with greater cylinder capacity led to an increase in consumption. Additionally, during this period there was a decrease in fuel prices which encouraged greater consumption (Gonzalez and Marrero, 2012). This led to a reduction of the energy efficiency of road traffic (rebound effect) and a rise in GHG emissions. Last but not least, during this period there was an important growth of the motorization rate and the employment rate, reaching their peak.

\subsection{Reaction to the economic crisis: $2007-2010$}

The economic crisis greatly affected the road transport sector. The four-year period of 2007-2010 was characterized by a reduction of GHG emissions in the transport sector after 17 years of steady increase. This analysis found that the most powerful drivers influencing the reduction were the use intensity - as road activity declined sharply - and energy and carbon efficiency (see Table 3). Road activity has been hit by the economic crisis, and people have 


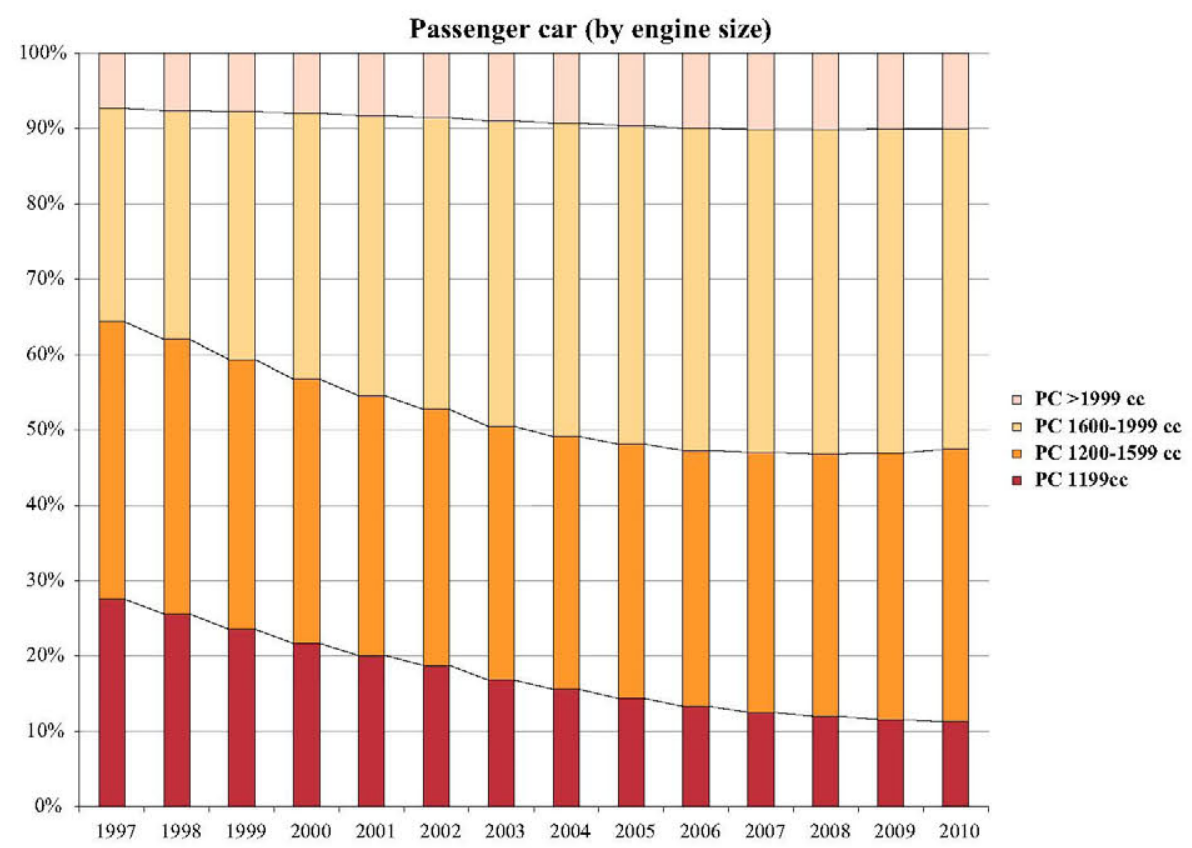

Fig. 8. Composition of passenger car fleet by engine capacity (DGT, 2011).

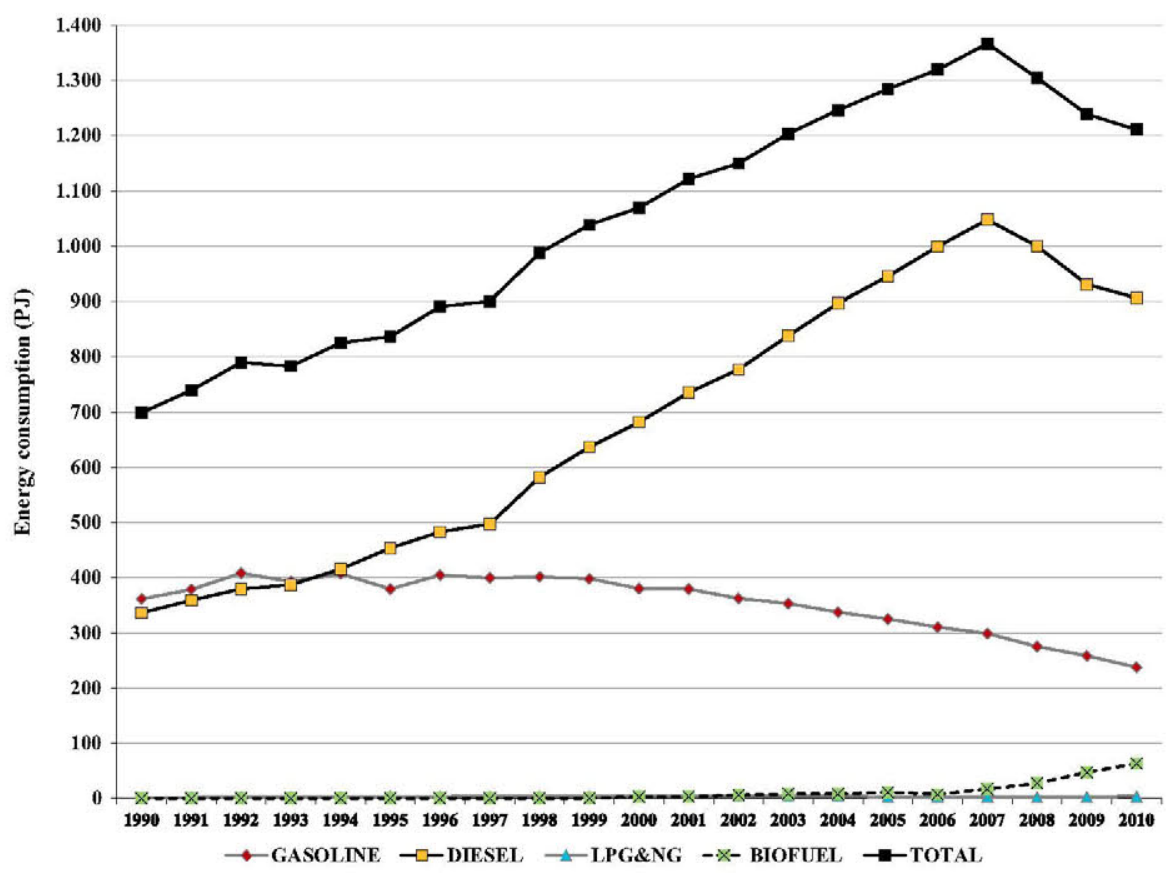

Fig. 9. Fuel mix of road transportation energy consumption in Spain (CNE, 2013).

reduced their travel distances and trips. Main factors influencing the use intensity have been: the reduction of employment rate and the reduction of income per capita (see Fig. 5). In this period, road energy consumption decreased due to an overall reduction of $15 \%$ in the use of oil products (Fig. 9). One of the reasons for this decrease was the rise in oil prices caused by the energy scarcity crisis (Mendiluce and Del Río, 2010). The improvement in energy efficiency and carbon efficiency, however, were also marked by the demand for biofuel. It has also increased in recent years (Fig. 9) because of the introduction of energy labeling in transport, the promotion of the use of biofuels (Spanish Government, 2008) and vehicle fleet renewal measures (IDAE, 2007). In fact, from 2008 to
2012, the tax-free policy for the use of biofuels increased demand for them, consequently improving carbon efficiency and reducing GHG emissions (a moderate reduction of carbon intensity can be observed in Fig. 6). In 2010, biodiesel represented 5.5\% of total diesel consumption and bioethanol made up $6 \%$ of total gasoline consumption.

\subsection{0 and beyond}

Since 2010, Spain has continued decreasing the GHG emissions from road transport, but these are currently maintained and they are not expected to grow. In 2011, Spain experienced an energy 
crisis and the government introduced special energy-saving strategies for the transport sector (MF, 2011). Additionally, the Second Energy Saving and Efficiency Action Plan 2011-2020 was launched, which also introduced a set of energy-saving measures for the transportation sector, mainly focused on the road transport mode (IDAE, 2011). Some of these measures are related to fleet renewal and several action plans have been implemented: the Efficient Vehicle Incentive Program: Plan PIVE - a plan to aid in purchasing smaller cars and light-duty vehicles - from 2012 (Spanish Government, 2013b) and the Comprehensive Strategy to Promote the Electric Vehicle in Spain 2010-2014: Plan MOVELE (Spanish Government, 2013a). Traffic activity has plateaued in Spain and is not expected to continue decreasing (MF, 2012); use intensity, then, does not seem to be contributing to the decrease in GHG emissions. Moreover, since January 2013, biofuels are no longer tax-free, which is a step back when it comes to the use of alternative fuels.

\subsection{Lessons from the crisis}

Finally, in order to decarbonize road transport and achieve the Kyoto Protocol target of returning to 1990 levels of GHG emissions (UNFCCC, 1998), the Spanish road transport sector will need to reduce emissions by $30 \mathrm{Mt} \mathrm{CO}_{2}$-eq (based on 2010 levels). It is clear that, as in the past, the priority is decoupling economic growth and energy consumption. New measures to reduce GHG emissions of road transport in Spain should take the following into consideration:

a) On the one hand, specific measures must continue to be taken to reduce the use of transport in general without compromising the country's development. This could be achieved by implementing policies oriented toward reducing demand and transferring activity to more energy-efficient modes (Banister, 2011).

b) On the other hand, as road traffic makes up the large majority of Spanish transport, there is a need for strategies to improve the efficiency of road use, such as traffic management strategies and penetration of smaller, more efficient vehicles to limit climate change. Speed management, improved infrastructure design, management of heavy-duty vehicles and efficient technologies (both efficient fuels and vehicles) are recommended (Monzon et al., 2012). Furthermore, specific analysis at an urban level should identify local drivers to define the best policy recommendations (i.e. Sobrino and Monzon, 2013).

\section{Conclusions and policy implications}

Road traffic is the greatest contributor to the carbon footprint of the transport sector. Global warming has been one the main concern in recent transportation policies and its reduction has become one of the main objectives of sustainable transport policies. An analysis of the main factors influencing energy consumption and GHG emissions is essential for designing new energy- and environmentally efficient strategies in the road transport mode. Decomposition analysis techniques have proved to be some of the most suitable methods for the assessment of transport trends (i.e. Lu et al. 2007).

This study presents a methodological framework to analyze the main factors influencing changes in the GHG emissions from road transport. First a review of the literature has identified three main groups of underlying factors: fuel efficiency, traffic activity and socioeconomic development. These can be separated into seven drivers: carbon intensity, energy intensity, road use intensity, motorization rate, job intensity, workers income intensity and GDP. The analysis of the drivers made use of index decomposition techniques, and the MLI method was chosen for its consistency in periods where large changes occur (i.e. changes in behavior, technology or the economy) as well as for its capacity to incorporate drivers which represent relationships between the underlying factors.

The methodology was applied to the Spanish road transport case study for the 1990-2010 period, which includes the beginning of the economic crisis. However, the proposed methodology can be applied to many different cases and can serve to benchmark strategies or compare countries. Hence, the MLI methodology has proven adequate for identifying relevant factors that affect $\mathrm{CO}_{2}$ emissions trends. The residual term has been eliminated from the decomposition, thereby improving on previous decomposition techniques.

The results highlight the main drivers influencing GHG emissions trends and four main periods have been identified: rapid motorization (1990-1997), dieselization effect (1997-2002), rapid economic growth and mileage increase (2002-2007) and the economic crisis (2007-2010). In summary, in 1990, the population of Spain began to purchase more cars, at a rate of approximately one vehicle per family; consequently, the increase in emissions in the first period was due to the rise in the motorization rate. In the second and third period, there were synergies between fiscal policies favoring diesel vehicles (lower taxes for new vehicles and diesel fuel) and the higher purchasing power of the population. The result was an increase in the motorization rate and the growth of the share of diesel vehicles in the Spanish fleet, as well as a rebound effect due to increased driving distances. This, in turn, caused a steady increase in energy consumption and GHG emissions, demonstrating the inefficiency of road transport systems during times of economic expansion and the importance of adopting adequate fiscal policies. From 2007 to the present, the economic crisis has led to a reduction of transport activity and higher energy efficiency on the road. People have adapted their behavior to their real mobility needs by reducing the number of kilometers they drive and moving more efficiently thanks to a renovated fleet.

In conclusion, Spain tends to be more efficient in a crisis that in prosperity; the country is at a crossroads which could mark a change in the paradigm of road transport. This study provides important information that could aid in developing measures and redefining strategies with which to take advantage of the recent decrease in the demand for road transport. Policy recommendations would include (a) returning to policies which encourage the purchase of smaller, more efficient vehicles in order to obtain a more energy-efficient vehicle fleet; (b) increasing the use of other transport modes and reducing car dependency through modal shift measures; and (c) encouraging efficient traffic management strategies and infrastructure design, and making use of information and communications technologies (ICT) for speed and traffic flow management. Future research would include a sensitivity analysis of different changes in the drivers and the assessment and comparison of different countries.

\section{Acknowledgments}

The authors would like to thank Yoshinori Mishina for his helpful comments on the use of the MLI decomposition analysis. N. Sobrino wishes to thank the Universidad Politécnica de Madrid (UPM) for the award of a research fellowship.

\section{Appendix A. Modified Laspeyres Index (MLI)}

This section develops the Modified Laspeyres Index (MLI) as presented by Mishina et al. (2011). Note that Eqs. (A.3) and (A.4) are provided also in the main text. 
In the seven change-factor model $\left(x_{1}, x_{2}, x_{3}, x_{4}, x_{5}, x_{6}, x_{7}\right)$, the change in the $x_{1}$ factor, which represents the change in GHG emissions $(\triangle \mathrm{GHG})$, is given by

$$
\begin{aligned}
& \Delta G H G_{x 1}=\Delta x_{1}\left(x_{2} x_{3} x_{4} x_{5} x_{6} x_{7}+\frac{a_{1}}{a_{1}+a_{2}} \Delta x_{2} x_{3} x_{4} x_{5} x_{6} x_{7}\right. \\
& +\frac{a_{1}}{a_{1}+a_{3}} \Delta x_{3} x_{2} x_{4} x_{5} x_{6} x_{7}+\frac{a_{1}}{a_{1}+a_{4}} \Delta x_{4} x_{2} x_{3} x_{5} x_{6} x_{7} \\
& +\frac{a_{1}}{a_{1}+a_{5}} \Delta x_{5} x_{2} x_{3} x_{4} x_{6} x_{7}+\frac{a_{1}}{a_{1}+a_{6}} \Delta x_{6} x_{2} x_{3} x_{4} x_{5} x_{7} \\
& +\frac{a_{1}}{a_{1}+a_{7}} \Delta x_{7} x_{2} x_{3} x_{4} x_{5} x_{6}+\frac{a_{1}}{a_{1}+a_{2}+a_{3}} \Delta x_{2} \Delta x_{3} x_{4} x_{5} x_{6} x_{7} \\
& +\frac{a_{1}}{a_{1}+a_{2}+a_{4}} \Delta x_{2} \Delta x_{4} x_{3} x_{5} x_{6} x_{7}+\frac{a_{1}}{a_{1}+a_{2}+a_{5}} \Delta x_{2} \Delta x_{5} x_{3} x_{4} x_{6} x_{7} \\
& +\frac{a_{1}}{a_{1}+a_{2}+a_{6}} \Delta x_{2} \Delta x_{6} x_{3} x_{4} x_{5} x_{7}+\frac{a_{1}}{a_{1}+a_{2}+a_{7}} \Delta x_{2} \Delta x_{7} x_{3} x_{4} x_{5} x_{6} \\
& +\frac{a_{1}}{a_{1}+a_{3}+a_{4}} \Delta x_{3} \Delta x_{4} x_{2} x_{5} x_{6} x_{7}+\frac{a_{1}}{a_{1}+a_{3}+a_{5}} \Delta x_{3} \Delta x_{5} x_{2} x_{4} x_{6} x_{7} \\
& +\frac{a_{1}}{a_{1}+a_{3}+a_{6}} \Delta x_{3} \Delta x_{6} x_{2} x_{4} x_{5} x_{7}+\frac{a_{1}}{a_{1}+a_{3}+a_{7}} \Delta x_{3} \Delta x_{7} x_{2} x_{4} x_{5} x_{6} \\
& +\frac{a_{1}}{a_{1}+a_{4}+a_{5}} \Delta x_{4} \Delta x_{5} x_{2} x_{3} x_{6} x_{7}+\frac{a_{1}}{a_{1}+a_{4}+a_{6}} \Delta x_{4} \Delta x_{6} x_{2} x_{3} x_{5} x_{7} \\
& +\frac{a_{1}}{a_{1}+a_{4}+a_{7}} \Delta x_{4} \Delta x_{7} x_{2} x_{3} x_{5} x_{6}+\frac{a_{1}}{a_{1}+a_{5}+a_{6}} \Delta x_{5} \Delta x_{6} x_{2} x_{3} x_{4} x_{7} \\
& +\frac{a_{1}}{a_{1}+a_{5}+a_{7}} \Delta x_{5} \Delta x_{7} x_{2} x_{3} x_{4} x_{6}+\frac{a_{1}}{a_{1}+a_{6}+a_{7}} \Delta x_{6} \Delta x_{7} x_{2} x_{3} x_{4} x_{5} \\
& +\frac{a_{1}}{a_{1}+a_{2}+a_{3}+a_{4}} \Delta x_{2} \Delta x_{3} \Delta x_{4} x_{5} x_{6} x_{7} \\
& +\frac{a_{1}}{a_{1}+a_{2}+a_{3}+a_{5}} \Delta x_{2} \Delta x_{3} \Delta x_{5} x_{4} x_{6} x_{7} \\
& +\frac{a_{1}}{a_{1}+a_{2}+a_{3}+a_{6}} \Delta x_{2} \Delta x_{3} \Delta x_{6} x_{4} x_{5} x_{7} \\
& +\frac{a_{1}}{a_{1}+a_{2}+a_{3}+a_{7}} \Delta x_{2} \Delta x_{3} \Delta x_{7} x_{4} x_{5} x_{6} \\
& +\frac{a_{1}}{a_{1}+a_{2}+a_{4}+a_{5}} \Delta x_{2} \Delta x_{4} \Delta x_{5} x_{3} x_{6} x_{7} \\
& +\frac{a_{1}}{a_{1}+a_{2}+a_{4}+a_{6}} \Delta x_{2} \Delta x_{4} \Delta x_{6} x_{3} x_{5} x_{7} \\
& +\frac{a_{1}}{a_{1}+a_{2}+a_{4}+a_{7}} \Delta x_{2} \Delta x_{4} \Delta x_{7} x_{3} x_{5} x_{6} \\
& +\frac{a_{1}}{a_{1}+a_{2}+a_{5}+a_{6}} \Delta x_{2} \Delta x_{5} \Delta x_{6} x_{3} x_{4} x_{7} \\
& +\frac{a_{1}}{a_{1}+a_{2}+a_{5}+a_{7}} \Delta x_{2} \Delta x_{5} \Delta x_{7} x_{3} x_{4} x_{6} \\
& +\frac{a_{1}}{a_{1}+a_{2}+a_{6}+a_{7}} \Delta x_{2} \Delta x_{6} \Delta x_{7} x_{3} x_{4} x_{5} \\
& +\frac{a_{1}}{a_{1}+a_{3}+a_{4}+a_{5}} \Delta x_{3} \Delta x_{4} \Delta x_{5} x_{2} x_{6} x_{7} \\
& +\frac{a_{1}}{a_{1}+a_{3}+a_{4}+a_{6}} \Delta x_{3} \Delta x_{4} \Delta x_{6} x_{2} x_{5} x_{7} \\
& +\frac{a_{1}}{a_{1}+a_{3}+a_{4}+a_{7}} \Delta x_{3} \Delta x_{4} \Delta x_{7} x_{2} x_{5} x_{6} \\
& +\frac{a_{1}}{a_{1}+a_{3}+a_{4}+a_{7}} \Delta x_{3} \Delta x_{4} \Delta x_{7} x_{2} x_{5} x_{6} \\
& +\frac{a_{1}}{a_{1}+a_{3}+a_{5}+a_{6}} \Delta x_{3} \Delta x_{5} \Delta x_{6} x_{2} x_{4} x_{7} \\
& +\frac{a_{1}}{a_{1}+a_{3}+a_{5}+a_{7}} \Delta x_{3} \Delta x_{5} \Delta x_{7} x_{2} x_{4} x_{6} \\
& +\frac{a_{1}}{a_{1}+a_{3}+a_{6}+a_{7}} \Delta x_{3} \Delta x_{6} \Delta x_{7} x_{2} x_{4} x_{5} \\
& +\frac{a_{1}}{a_{1}+a_{4}+a_{5}+a_{6}} \Delta x_{4} \Delta x_{5} \Delta x_{6} x_{2} x_{3} x_{7} \\
& +\frac{a_{1}}{a_{1}+a_{4}+a_{5}+a_{7}} \Delta x_{4} \Delta x_{5} \Delta x_{7} x_{2} x_{3} x_{6} \\
& +\frac{a_{1}}{a_{1}+a_{4}+a_{6}+a_{7}} \Delta x_{4} \Delta x_{6} \Delta x_{7} x_{2} x_{3} x_{5} \\
& +\frac{a_{1}}{a_{1}+a_{5}+a_{6}+a_{7}} \Delta x_{5} \Delta x_{6} \Delta x_{7} x_{2} x_{3} x_{4}
\end{aligned}
$$

$$
\begin{aligned}
& +\frac{a_{1}}{a_{1}+a_{2}+a_{3}+a_{4}+a_{5}} \Delta x_{2} \Delta x_{3} \Delta x_{4} \Delta x_{5} x_{6} x_{7} \\
& +\frac{a_{1}}{a_{1}+a_{2}+a_{3}+a_{4}+a_{6}} \Delta x_{2} \Delta x_{3} \Delta x_{4} \Delta x_{6} x_{5} x_{7} \\
& +\frac{a_{1}}{a_{1}+a_{2}+a_{3}+a_{4}+a_{7}} \Delta x_{2} \Delta x_{3} \Delta x_{4} \Delta x_{7} x_{5} x_{6} \\
& +\frac{a_{1}}{a_{1}+a_{2}+a_{3}+a_{5}+a_{6}} \Delta x_{2} \Delta x_{3} \Delta x_{5} \Delta x_{6} x_{4} x_{7} \\
& +\frac{a_{1}}{a_{1}+a_{2}+a_{3}+a_{5}+a_{7}} \Delta x_{2} \Delta x_{3} \Delta x_{5} \Delta x_{7} x_{4} x_{6} \\
& +\frac{a_{1}}{a_{1}+a_{2}+a_{3}+a_{6}+a_{7}} \Delta x_{2} \Delta x_{3} \Delta x_{6} \Delta x_{7} x_{4} x_{5} \\
& +\frac{a_{1}}{a_{1}+a_{2}+a_{4}+a_{5}+a_{6}} \Delta x_{2} \Delta x_{4} \Delta x_{5} \Delta x_{6} x_{3} x_{7} \\
& +\frac{a_{1}}{a_{1}+a_{2}+a_{4}+a_{5}+a_{7}} \Delta x_{2} \Delta x_{4} \Delta x_{5} \Delta x_{7} x_{3} x_{6} \\
& +\frac{a_{1}}{a_{1}+a_{2}+a_{4}+a_{6}+a_{7}} \Delta x_{2} \Delta x_{4} \Delta x_{6} \Delta x_{7} x_{3} x_{5} \\
& +\frac{a_{1}}{a_{1}+a_{2}+a_{5}+a_{6}+a_{7}} \Delta x_{2} \Delta x_{5} \Delta x_{6} \Delta x_{7} x_{3} x_{4} \\
& +\frac{a_{1}}{a_{1}+a_{3}+a_{4}+a_{5}+a_{6}} \Delta x_{3} \Delta x_{4} \Delta x_{5} \Delta x_{6} x_{2} x_{7} \\
& +\frac{a_{1}}{a_{1}+a_{3}+a_{4}+a_{5}+a_{7}} \Delta x_{3} \Delta x_{4} \Delta x_{5} \Delta x_{7} x_{2} x_{6} \\
& +\frac{a_{1}}{a_{1}+a_{3}+a_{4}+a_{6}+a_{7}} \Delta x_{3} \Delta x_{4} \Delta x_{6} \Delta x_{7} x_{2} x_{5} \\
& +\frac{a_{1}}{a_{1}+a_{3}+a_{5}+a_{6}+a_{7}} \Delta x_{3} \Delta x_{5} \Delta x_{6} \Delta x_{7} x_{2} x_{4} \\
& +\frac{a_{1}}{a_{1}+a_{4}+a_{5}+a_{6}+a_{7}} \Delta x_{4} \Delta x_{5} \Delta x_{6} \Delta x_{7} x_{2} x_{3} \\
& +\frac{a_{1}}{a_{1}+a_{2}+a_{3}+a_{4}+a_{5}+a_{6}} \Delta x_{2} \Delta x_{3} \Delta x_{4} \Delta x_{5} \Delta x_{6} x_{7} \\
& +\frac{a_{1}}{a_{1}+a_{2}+a_{3}+a_{4}+a_{5}+a_{7}} \Delta x_{2} \Delta x_{3} \Delta x_{4} \Delta x_{5} \Delta x_{7} x_{6} \\
& +\frac{a_{1}}{a_{1}+a_{2}+a_{3}+a_{4}+a_{6}+a_{7}} \Delta x_{2} \Delta x_{3} \Delta x_{4} \Delta x_{6} \Delta x_{7} x_{5} \\
& +\frac{a_{1}}{a_{1}+a_{2}+a_{3}+a_{5}+a_{6}+a_{7}} \Delta x_{2} \Delta x_{3} \Delta x_{5} \Delta x_{6} \Delta x_{7} x_{4} \\
& +\frac{a_{1}}{a_{1}+a_{2}+a_{4}+a_{5}+a_{6}+a_{7}} \Delta x_{2} \Delta x_{4} \Delta x_{5} \Delta x_{6} \Delta x_{7} x_{3} \\
& +\frac{a_{1}}{a_{1}+a_{3}+a_{4}+a_{5}+a_{6}+a_{7}} \Delta x_{3} \Delta x_{4} \Delta x_{5} \Delta x_{6} \Delta x_{7} x_{2} \\
& \left.+\frac{a_{1}}{a_{1}+a_{2}+a_{3}+a_{4}+a_{5}+a_{6}+a_{7}} \Delta x_{2} \Delta x_{3} \Delta x_{4} \Delta x_{5} \Delta x_{6} \Delta x_{7}\right)
\end{aligned}
$$

where

$a_{i}=\frac{\Delta x_{i}}{\frac{x_{i}^{0}+x_{i}^{i}}{2}} \quad(i=1,2,3,4,5,6,7)$

$\Delta x_{i}=x_{i}^{t}-x_{i}^{0} \quad(i=1,2,3,4,5,6,7)$

and $x_{i}$ is the driver under consideration. When the factor $x_{1}$ does not change for the period $[0, t]$, the symmetric rate of change $\left(a_{1}\right)$ of the factor $x_{1}$ is zero. Hence, the change in GHG for the period $0-t$ is expressed as

$$
\begin{aligned}
\Delta G H G= & \Delta G H G_{X 1}+\Delta G H G_{X 2}+\Delta G H G_{X 3}+\Delta G H G_{X 4} \\
& +\Delta G H G_{X 5}+\Delta G H G_{X 6}+\Delta G H G_{X 7}
\end{aligned}
$$

The time-series decomposition consists of yearly comparisons and addition of the results over a specific period.

\section{Appendix B. Spanish road transport data}

See Table B1. 
Table B1

Factor figures.

\begin{tabular}{|c|c|c|c|c|c|c|c|}
\hline Year & $\begin{array}{l}\text { GHG emission from road } \\
\text { transport in Spain } \\
\mathrm{tCO}_{2} \text {-eq } \\
Q\end{array}$ & $\begin{array}{l}\text { Total Energy consumption in } \\
\text { Spain from road transport } \\
\text { TJ } \\
\text { EC }\end{array}$ & $\begin{array}{l}\text { Total distance driven in } \\
\text { Spanish road by vehicles } \\
10^{6} \mathrm{~km} \\
T\end{array}$ & $\begin{array}{l}\text { Total Spanish } \\
\text { vehicle fleet } \\
10^{3} \text { veh } \\
\text { VF }\end{array}$ & $\begin{array}{l}\text { Spanish } \\
\text { population } \\
10^{3} \text { Inhab } \\
P\end{array}$ & $\begin{array}{l}\text { Employed } \\
\text { population } \\
10^{3} \text { Inhab } \\
\text { EP }\end{array}$ & $\begin{array}{l}\text { Spanish Gross } \\
\text { Domestic Product } \\
10^{6} \text { Euro } \\
\text { GDP }\end{array}$ \\
\hline 1990 & $51,244,000$ & 699,000 & 183,500 & 16,834 & 38,826 & 13,967 & $468,206.2$ \\
\hline 1991 & $54,181,000$ & 739,200 & 193,800 & 17,768 & 38,875 & 13,967 & $480,114.6$ \\
\hline 1992 & $57,881,000$ & 789,900 & 209,800 & 18,640 & 39,004 & 13,772 & $484,580.9$ \\
\hline 1993 & $57,383,000$ & 782,900 & 209,400 & 19,145 & 39,132 & 13,381 & $479,583.3$ \\
\hline 1994 & $60,542,000$ & 825,400 & 225,000 & 19,552 & 39,247 & 13,318 & $491,011.7$ \\
\hline 1995 & $61,400,000$ & 836,600 & 231,600 & 20,158 & 39,343 & 13,569 & $515,405.0$ \\
\hline 1996 & $65,446,000$ & 891,000 & 248,800 & 20,863 & 39,431 & 13,796 & $527,564.2$ \\
\hline 1997 & $66,190,000$ & 900,600 & 259,000 & 21,603 & 39,525 & 14,293 & $547,974.1$ \\
\hline 1998 & $72,630,000$ & 987,400 & 285,500 & 22,631 & 39,639 & 14,932 & $572,458.4$ \\
\hline 1999 & $76,466,000$ & $1,038,600$ & 303,800 & 23,745 & 39,803 & 15,617 & $599,626.9$ \\
\hline 2000 & $78,494,000$ & $1,069,100$ & 312,400 & 24,612 & 40,050 & 16,412 & $629,907.0$ \\
\hline 2001 & $81,784,000$ & $1,121,700$ & 327,500 & 25,599 & 40,477 & 16,942 & $653,021.0$ \\
\hline 2002 & $83,581,000$ & $1,149,800$ & 339,600 & 26,606 & 40,964 & 17,359 & $670,719.1$ \\
\hline 2003 & $87,365,000$ & $1,203,900$ & 358,400 & 26,761 & 41,664 & 17,916 & $691,440.5$ \\
\hline 2004 & $90,440,000$ & $1,246,300$ & 358,300 & 28,054 & 42,345 & 18,565 & $713,976.7$ \\
\hline 2005 & $92,968,000$ & $1,284,500$ & 371,700 & 29,272 & 43,038 & 19,335 & $739,563.1$ \\
\hline 2006 & $95,833,000$ & $1,319,600$ & 384,900 & 30,104 & 43,758 & 20,105 & $769,709.3$ \\
\hline 2007 & $98,584,000$ & $1,366,700$ & 398,700 & 31,907 & 44,475 & 20,713 & $796,488.9$ \\
\hline 2008 & $93,309,000$ & $1,304,600$ & 384,500 & 32,516 & 45,283 & 20,687 & $803,567.0$ \\
\hline 2009 & $87,031,000$ & $1,239,100$ & 376,900 & 32,339 & 45,828 & 19,338 & $773,507.5$ \\
\hline 2010 & $83,872,000$ & $1,210,900$ & 376,100 & 32,501 & 45,989 & 18,856 & $772,970.1$ \\
\hline
\end{tabular}

\section{References}

Ang, B., Choi, K., 1997. Decomposition of aggregate energy and gas emission intensities for industry: a refined divisia index method. Energy J. 18 (3), 59-73.

Ang, B.W., Zhang, F.O., Choi, K., 1998. Factorizing changes in energy and environmental indicators through decomposition. Energy 23 (6), 489-495. http://dx. doi.org/10.1016/S0360-5442(98)00016-4.

Ang, B.W., Zhang, F.Q., 2000. A survey of index decomposition analysis in energy and environmental studies. Energy 25 (12), 1149-1176. http://dx.doi.org/ 10.1016/S0360-5442(00)00039-6.

Ang, B.W., Liu, F.L., 2001. A new energy decomposition method: perfect in decomposition and consistent in aggregation. Energy 26 (6), 537-548. http: //dx.doi.org/10.1016/S0360-5442(01)00022-6.

Ang, B.W., 2004. Decomposition analysis for policymaking in energy: which is the preferred method? Energy Policy 32 (9), 1131-1139. http://dx.doi.org/10.1016/ S0301-4215(03)00076-4

Ang, B.W., Huang, H.C., Mu, A.R., 2009. Properties and linkages of some index decomposition analysis methods. Energy Policy 37 (11), 4624-4632. http://dx. doi.org/10.1016/j.enpol.2009.06.017.

Banister, D, 2011. The trilogy of distance, speed and time. J. Transp. Geogr. 19, 950-959. http://dx.doi.org/10.1016/j.jtrangeo.2010.12.004.

CNE, 2013. Estudio sobre las emisiones derivadas del consumo de carburantes en el transporte por carretera en España. Comisión Nacional de Energia, Dirección de Hidrocarburos. Retrieved June 2013 from $\langle$ http://www.cne.es/cne/contenido. jsp?id_nodo=525\&\&\&keyword-\&auditoria=F .

DGT, 2011. Anuario Estadístico General. Dirección General de Tráfico. Retrieved June 2013 from 〈http://www.dgt.es/was6/portal/contenidos/es/seguridad_vial/esta distica/publicaciones/anuario general/anuario general016.pdf).

EUROSTAT, 2013a. Final Energy Consumption by Sector. Retrieved November 2013 from 〈http://www.epp.eurostat.ec.europa.eu/tgm/table.do?tab=table\&init= 1 \&language $=$ en $\&$ pcode $=$ tsdpc 320 \& plugin $=1\rangle$.

EUROSTAT, 2013b. Greenhouse Gas Emissions by Sector. Retrieved May 2013 from (http://www.epp.eurostat.ec.europa.eu/tgm/table.do? tab $=$ table\&init $=1$ \&language $=$ en\&pcode $=$ ten00072\&plugin $=1\rangle$.

Gonzalez, R.M., Marrero, G.A., 2012. The effect of dieselization in passenger cars emissions for Spanish regions: 1998-2006. Energy Policy 51, 213-222. http: //dx.doi.org/10.1016/j.enpol.2012.03.033.

He, K., Huo, H., Zhang, Q., He, D., An, F., Wang, M., Walsh, M., 2005. Oil consumption and $\mathrm{CO}_{2}$ emissions in China's road transport: current status, future trends, and policy implications. Energy Policy 33 (12), 1499-1507. http://dx.doi.org/ 10.1016/j.enpol.2004.01.007.

Idea, 2011. Saving and Energy Efficiency Action Plan 2011-2020. Retrieved June 2012 from 〈http://www.idae.es/index.php/id.663/lang.uk/relmenu.332/mod. pags/mem.detalle).

IDAE, 2007. Action Plan 2008-2012, Saving and Energy Efficiency Strategies in Spain E4 2004-2012, IDAE. Retrieved June 2013 from 〈http://www.idae.es/ index.php/mod.documentos/mem.descarga?file=/documentos_Plan_de_Ac cion_2008-2012_19-07-07_con_TABLAS PDF_ACC_2936ad7f.pdf).
INE, 2013. Instituto Nacional de Estadística. Retrieved May 2013 from 〈http://www. ine.es>.

Kwon, T., 2005. Decomposition of factors determining the trend of $\mathrm{CO}_{2}$ emissions from car travel in Great Britain (1970-2000). Ecol. Econ. 53 (2), 261-275. http: //dx.doi.org/10.1016/j.ecolecon.2004.06.028.

Lakshmanan, T.R., Han, X., 1997. Factors underlying transportation CO2 emissions in the U.S.A; A decomposition analysis. Transp. Res. Part D: Transp. Environ 2. 1-15. http://dx.doi.org/10.1016/\$1361-9209(96)00011-9.

Li, H., Lu, Y., Zhang, J., Wang, T., 2013. Trends in road freight transportation carbon dioxide emissions and policies in China. Energy Policy 57, 99-106. http://dx. doi.org/10.1016/j.enpol.2012.12.070.

Lipscy, P.Y., Schipper, L., 2013. Energy efficiency in the Japanese transport sector. Energy Policy 56, 248-258. http://dx.doi.org/10.1016/j.enpol.2012.12.045.

Lu, I.J., Lin, S.J., Lewis, C., 2007. Decomposition and decoupling effects of carbon dioxide emission from highway transportation in Taiwan, Germany, Japan and South Korea. Energy Policy 35 (6), 3226-3235. http://dx.doi.org/10.1016/j. enpol.2006.11.003.

MAGRAMA, 2012. Inventario de gases de efecto invernadero de España Edición 2012 (Serie 1990-2010), Ministerio de Agricultura, Alimentación y Medio Ambiente. Retrieved May 2013 from 〈http://www.magrama.gob.es/es/calida d-y-evaluacion-ambiental/temas/sistema-espanol-de-inventario-sei>

Mazzarino, M., 2000. The economics of the greenhouse effect: evaluating the climate change impact due to transport sector in Italy. Energy Policy 28 , 957-966. http://dx.doi.org/10.1016/S0301-4215(00)00078-1.

Mendiluce, M., Perez-Arriaga, I., Ocaña, C., 2010. Comparison of the evolution of energy intensity in Spain and in the EU15. Why is Spain different? Energy Policy 38 (1), 639-645. http://dx.doi.org/10.1016/j.enpol.2009.07.069.

Mendiluce, M., Del Río, P., 2010. Energía y transporte. Cuadernos Económicos De ICE 79, 213-236.

Mendiluce, M., Schipper, L., 2011. Trends in passenger transport and freight energy use in Spain. Energy Policy 39 (10), 6466-6475. http://dx.doi.org/10.1016/j. enpol 2011.07 .048$.

MF, 2012. Anuario estadístico 2011. Ministerio de Fomento (MF). Retrieved June 2013 from 〈www.fomento.gob.es〉.

MF. (2011) Plan de ahorro, eficiencia energética y reducción de emisiones en el transporte y la vivienda. Ministerio de Fomento (MF). Retrieved June 2013 from 〈www.fomento.gob.es〉.

Mishina, Y., Taniguchi, Y., Muromachi, Y., 2011. Why carbon dioxide emissions from Japanese passenger cars peaked in 2001 complete decomposition analysis from 1990 to 2008. Transp. Res. Rec. 2252, 152-160. http://dx.doi.org/10.3141/2252-19.

Mishina, Y., Muromachi, Y., 2012. Revisiting decomposition analysis for carbon dioxide emissions from car travel introduction of Modified Laspeyres Index method. Transp. Res. Rec. 2270, 171-179. http://dx.doi.org/10.3141/2270-20.

Monzon, A., Sobrino, N., Hernandez, S., 2012. Energy -and environmentally efficient road management: the case of the Spanish motorway network. Proc. Soc. Behav. Sci. 48 (0), 287-296. http://dx.doi.org/10.1016/j.sbspro.2012.06.1009.

ODYSSEE, 2012. Energy Efficiency Indicators in Europe. Retrieved June 2013 from 〈www.odyssee-indicators.org $\rangle$. 
Papagiannaki, K., Diakoulaki, D., 2009. Decomposition analysis of $\mathrm{CO}_{2}$ emissions from passenger cars: the cases of Greece and Denmark. Energy Policy 37 (8) 3259-3267. http://dx.doi.org/10.1016/j.enpol.2009.04.026.

Pérez-López, P., Gasol, C.M., Oliver-Sola, J., Huelin, S., Teresa Moreira, M., Feijoo, G., 2013. Greenhouse gas emissions from Spanish motorway transport: key aspects and mitigation solutions. Energy Policy 60, 705-713. http://dx.doi.org/10.1016/j. enpol.2013.04.075

Pérez-Martínez, P.J., Monzón, A., 2008. Consumo de energía por el transporte en España, tendencias de emisión. Obs. Medioambient. 11, 127-141.

Pérez-Martínez, P.J., 2010. Freight transport, energy use, and emission trends in Spain. Transp. Res. Rec: J. Transp. Res. Board 2191 (1), 16-22.

Piecyk, M.l., McKinnon, A.C., 2010. Forecasting the carbon footprint of road freight transport in 2020. Int. J. Prod. Econ. 128 (1), 31-42. http://dx.doi.org/10.1016/j. ijpe.2009.08.027.

Schipper, L., Marie-Lilliu, C., Gorham, R., 2000. Flexing the Link Between Transport and Greenhouse gas Emissions a path for the World Bank. International Energy Agency. 〈http://www.ocs.polito.it/biblioteca/mobilita/FlexingLink1.pdf) (retrieved June 2013).

Schipper, L., Saenger, C., Sudardshan, A., 2011. Transport and carbon emissions in the United States: the long view. Energies 4, 563-581. http://dx.doi.org/ $10.3390 /$ en 4040563 .

Scholl, L., Schipper, L., Kiang, N., 1996. $\mathrm{CO}_{2}$ emissions from passenger transport: a comparison of international trends from 1973 to 1992. Energy Policy 24, 17-30. http://dx.doi.org/10.1016/0301-4215(95)00148-4.

Spanish Government, 2013a. Estrategia integral para el impulso del vehículo eléctrico en España 2010-2014. BOE, 101, 1, 32072 〈http://www.boe.es/boe/ dias/2013/04/27/pdfs/BOE-A-2013-4461.pdf).

Spanish Government, 2013b. Programa de incentivos al vehículo eficiente PIVE 3 BOE, 179, 8189 〈http://www.boe.es/boe/dias/2013/07/27/pdfs/BOE-A-20138189.pdI).

Spanish Government, 2008. ORDEN ITC/2877/2008, de 9 de octubre, por la que se establece un mecanismo de fomento del uso de biocarburantes y otros combustibles renovables con fines de transporte. BOE 248, 16487, 4177041775 〈http://www.boe.es/boe/dias/2008/10/14/pdfs/A41170-41175.pdf)

Spanish Government, 1997. Programa PREVER para la modernización del parque de vehículos automóviles, el incremento de la seguridad vial y la defensa y protección del medio ambiente. BOE, 243, 29458-29460 〈http://www.boe.es/ diario boe/txt.php?id=BOE-A-1997-21521>.

Sobrino, N., Monzon, A., 2013. Management of urban mobility to control climate change in cities. Transp. Res. Rec.: J. Transp. Res. Board 2375, 55-61. http://dx. doi.org/10.3141/2375-07.

Sun, J., 1998. Changes in energy consumption and energy intensity: a complete decomposition model. Energy Econ. 20 (1), 85-100. http://dx.doi.org/10.1016/ S0140-9883(97)00012-1.

Timilsina, G.R., Shrestha, A., 2009a. Factors affecting transport sector $\mathrm{CO}_{2}$ emissions growth in Latin American and Caribbean countries: an LMDI decomposition analysis. Int. J. Energy Res. 33, 396-414. http://dx.doi.org/10.1002/er.1486.

Timilsina, G.R., Shrestha, A., 2009b. Transport sector $\mathrm{CO}_{2}$ emissions growth is Asia: underlying factors and policy options. Energy Policy 37, 4523-4539. http://dx. doi.org/10.1016/j.enpol.2009.06.009.

UNFCCC, 1998. Kyoto Protocol to the United Nations Framework Convention on Climate Change (UNFCCC)

Wang, W.W., Zhang, M., Zhou, M., 2011. Using LMDI method to analyze transport sector $\mathrm{CO}_{2}$ emissions in China. Energy 36, 5909-5915. http://dx.doi.org/ 10.1016/j.energy.2011.08.031.

WCED, 1987. Our common future, Report of the World Commission on Environment and Development (the Brundtland Report). Oxford University Press, New York.

Yan, X., Crookes, R.J., 2009. Reduction potentials of energy demand and GHG emissions in China's road transport sector. Energy Policy 37 (2), 658-668. http: //dx.doi.org/10.1016/j.enpol.2008.10.008.

Zhang, M., Li, H., Zhou, M., Mu, H., 2011. Decomposition analysis of energy consumption in Chinese transportation sector. Appl. Energy 88, 2279-2285. http://dx.doi.org/10.1016/j.apenergy.2010.12.077. 